\title{
Exogenous nitric oxide inhibits shedding of ADAM17 substrates
}

\author{
Monika Bzowska, Krystyna Stalińska, Renata Mężyk-Kopeć, Karolina Wawro, \\ Katarzyna Duda, Sudipta Das and Joanna Bereta ${ }^{\varpi}$ \\ Department of Cell Biochemistry, Faculty of Biochemistry, Biophysics and Biotechnology, \\ Jagiellonian University, Kraków, Poland
}

Received: 07 April, 2009; revised: 28 May, 2009; accepted: 17 June, 2009

available on-line: 18 June, 2009

\begin{abstract}
Both ADAM17, the secretase responsible for the shedding of ectodomains of numerous membrane proteins including TNF and its receptors, as well as nitric oxide synthesized by inducible nitric oxide synthase play regulatory roles in inflammation and tumor progression. We analyzed the effect of endogenous and exogenous nitric oxide on the expression and activity of ADAM17 in murine endothelial cells and a monocyte/macrophage cell line. We found that endogenous nitric oxide influenced neither ADAM17 mRNA level nor the shedding of two ADAM17 substrates, TNF and TNFR1. Exogenous NO significantly diminished the release of TNF and TNFR1 without affecting the ADAM17 transcript level. Our data seem contrary to a previous report that showed the activation of ADAM17 by nitric oxide (Zhang et al., 2000, J Biol Chem 275: 15839-15844). We discuss potential mechanisms of NO-mediated inhibition of ectodomain shedding and possible reasons of discrepancy between our results and the previous report.
\end{abstract}

Keywords: nitric oxide, ADAM17, shedding, TNF, TNF receptor 1

\section{INTRODUCTION}

ADAM17, also known as TACE (tumor necrosis factor- $\alpha$ converting enzyme), has been identified as the main secretase responsible for releasing the soluble form of tumor necrosis factor (TNF) from the plasma membrane. It belongs to the ADAM (a disintegrin and metalloprotease domain) family of transmembrane, multidomain zinc metalloproteinases (Black et al., 1997; Moss et al., 1997). ADAM17 plays a vital role in development through the processing of numerous growth factors and growth factor receptors (Arribas \& Ruiz-Paz, 2005) and in immunoregulation through the shedding of TNF, as well as ectodomains of both TNF receptors (Peschon et al., 1998; Reddy et al., 2000), interleukin (IL)-1-RII (Reddy et al., 2000), IL-6-R $\alpha$ (Althoff et al., 2000), L-selectin (Peschon et al., 1998), vascular cell adhesion molecule-1 (VCAM-1) (Garton et al., 2001; 2003), fractalkine (Garton et al., 2001) and others (Arribas \& Ruiz-Paz, 2005). Thus, the effect of ADAM17 on the immune system seems to be complex. Its activity towards TNF and IL-6R $\alpha$ could potentiate the proinflammatory effects of the cytokines, whereas shedding of TNF receptors, IL-1-RII, and cell adhesion molecules should limit the inflammatory response (Mężyk et al., 2003). The proinflammatory activity of ADAM17 was well documented by in vivo studies of Horiuchi et al. (2007) who showed that conditional knockout mice lacking ADAM17 in myeloid cells are resistant to endotoxin shock, presumably due to limited shedding of TNF. The activity of ADAM17 is strongly enhanced by phorbol esters, and although the mechanism of this process has been extensively investigated, it is still poorly understood (Arribas \& Ruiz-Paz, 2005). The expression of ADAM17 was shown to be increased in vitro in different cell types exposed to proinflammatory cytokines $(\mathrm{Xu}$ et

\footnotetext{
Corresponding author: Joanna Bereta, Faculty of Biochemistry, Biophysics and Biotechnology, Jagiellonian University, Gronostajowa 7, 30-387 Kraków, Poland; fax: (48) 12664 6902; e-mail: joanna.bereta@uj.edu.pl

^Presented at the XXXVI Winter School "Molecule interactions in health and disease" organized by the Faculty of Biochemistry, Biophysics and Biotechnology, Jagiellonian University, 21-26 February, 2009, Zakopane, Poland.

Abbreviations: ADAM17, a disintegrin and metalloprotease 17; IFN $\gamma$, interferon $\gamma$; IL-1 $\beta$, interleukin 1 $\beta$; LPS, lipopolysaccharide; MMPs, matrix metalloproteases; RNS, reactive nitrogen species; PMA, phorbol 12-myristate 13-acetate; TNF, tumor necrosis factor; TNFR1; tumor necrosis factor receptor 1.
} 
al., 2002; Bzowska et al., 2004; Gomez et al., 2005) as well as in vivo in different cells and tissues under inflammatory conditions (Colon et al., 2001; Bohgaki et al., 2005; Kermarrec et al., 2005). A highly increased expression of ADAM17 is also characteristic for numerous types of tumors (Borrell-Pages et al., 2003; Ding et al., 2004; Blanchot-Jossic et al., 2005) and an involvement of this secretase in tumor progression has been implied by certain studies (Franovic et al., 2006).

Nitric oxide is produced in large quantities by inducible nitric oxide synthase expressed during inflammation in various cell types, including macrophages and endothelial cells. This smallest natural signaling molecule has bactericidal activity (Murray \& Nathan, 1999; Eriksson et al., 2003) but it is also involved in the regulation of immune system functioning; for instance, it inhibits T-cell proliferation and differentiation, B-cell proliferation and antibody production, as well as modulates the expression of some cytokines and inhibits the endothelial expression of cell adhesion molecules, thus limiting the adherence of leukocytes to the endothelium and their migration to the sites of injury (Bogdan, 2001). NO produced in excess can be harmful to the host. It is partly responsible for LPS-induced hypotension and multiple organ dysfunction (MacMicking et al., 1995). Nitric oxide is also produced in tumors by tumor-associated macrophages or due to the expression of iNOS in tumor cells. Depending on tumor cell type and tumor microenvironment it may lead to an inhibition of tumor growth or, on the contrary, to tumor progression, which partially results from nitric oxide-stimulated tumor neovascularization (Bogdan, 2001).

Nitric oxide derived from an $\mathrm{NO}$ donor has been shown to activate ADAM17 (Zhang et al., 2000). However, since both molecules play important roles in inflammation and tumor growth, and nitric oxide has diverse effects on various cellular processes, we decided to investigate the effect of endogenous and exogenous nitric oxide on the expression and activity of ADAM17 in endothelial cells and cells of monocyte/macrophage origin.

\section{MATERIALS AND METHODS}

Murine cell lines. MBE-SV, murine brain microvascular endothelial cells (a gift from Dr. R. Auerbach, Madison, WI, USA) immortalized with SV40 large $\mathrm{T}$ antigen; P388/D1, murine monocyte/macrophage cell line (ATCC\#CCL-46); ADAM17 ${ }^{--} \mathrm{TNF}^{+}$, Ras-Myc-immortalized murine fibroblasts isolated from ADAM17 $\triangle Z n / \Delta Z n$ mice, a gift from Dr. R. A. Black (Amgen Inc., Seattle, WA, USA) stably trans- fected with human proTNF cDNA (Mężyk-Kopeć et al., 2005).

Chemicals. Antibodies: murine monoclonal anti-human TNF (Biocentrum Ltd., Kraków, Poland), rabbit polyclonal anti-human TNF (Sigma), rabbit polyclonal anti-murine TNFR1 (Santa Cruz), horseradish peroxidase (HRP)-conjugated anti-murine IgG (Sigma), FITC-conjugated anti-murine IgG (Sig$\mathrm{ma})$; NO donors: $S$-nitroso- $N$-acetylpenicillamine (SNAP) (Sigma) and (Z)-1-[N-(2-aminopropyl)- $N$ (2-ammoniopropyl)amino]-diazen-1-ium-1,2-diolate

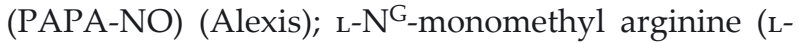
NMMA) and $\mathrm{D}-\mathrm{N}^{\mathrm{G}}$-monomethyl arginine $\mathrm{D}$-NMMA (Alexis). Cytokines: recombinant human (rh) TNF (Suntory Pharmaceuticals), rhIL-1 $\beta$ (Sigma), recombinant murine (rm) IFN $\gamma$ (Genzyme). Plasmid pcDNA3.1 coding for muADAM17 (pcDNA3.1/muADAM17) was a gift from Dr. R. A. Black (Amgen Inc.).

Cell cultures. All cell lines were cultured in DMEM/Glutamax-1 supplemented with $10 \%$ FBS at $37^{\circ} \mathrm{C}$ in $5 \% \mathrm{CO}_{2}$. Culture medium for ADAM17-/$\mathrm{TNF}^{+}$cells was enriched in geneticin $(1.5 \mathrm{mg} / \mathrm{ml})$ and in zeocin $(500 \mu \mathrm{g} / \mathrm{ml})$ every few passages.

Analysis of the influence of endogenous nitric oxide on shedding of ADAM17 substrates. The cells were incubated in 96-well plates for $24 \mathrm{~h}$ in DMEM enriched in 2\% FCS containing cytokines in order to stimulate iNOS expression. MBE-SV cells were stimulated with rhTNF $(10 \mathrm{ng} / \mathrm{ml})$, rhIL-1 $\beta$ (10 $\mathrm{ng} / \mathrm{ml})$ and $\mathrm{rmIFN} \gamma(200 \mathrm{U} / \mathrm{ml})$ and P388/D1 cells with rhIL-1 $\beta$ and $\operatorname{rmIFN} \gamma$ and additionally LPS $(100 \mathrm{ng} / \mathrm{ml})$. To some experimental groups an iNOS

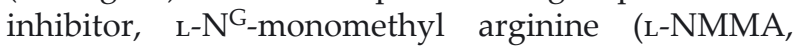
$2 \mathrm{mM}$ ) or its non-active stereoisomer, D-NMMA $(2 \mathrm{mM})$, was added. After $24 \mathrm{~h}$ the medium was replaced with fresh DMEM (2\% FCS), ADAM17 activity was stimulated by the addition of PMA $(250 \mathrm{nM})$ and the cells were incubated for additional $45 \mathrm{~min}$. The concentrations of TNF in the media of P388/D1 cells were measured by ELISA using BenderMedSystem (Vien, Austria). For the measurement of TNFR1 shedding, the MBE-SV cells were biotinylated using a standard protocol (Ausubel et al., 1995) prior to PMA activation. The levels of biotinylated TNFR1 in the media of MBE-SV cells were estimated by ELISA using polyclonal anti-mouse TNFR1 as a capture antibody $(5 \mu \mathrm{g} / \mathrm{ml})$ and $\mathrm{HRP}$-conjugated streptavidin $(1: 10000)$ as a detection molecule.

Analysis of the influence of exogenous nitric oxide on shedding of ADAM17 substrates. MBE$\mathrm{SV}$ cells and ADAM17---TNF${ }^{+}$cells were incubated for 6 or $24 \mathrm{~h}$ in the presence of different concentrations of SNAP or for $3 \mathrm{~h}$ in the presence of different concentrations of PAPA-NO. P388/D1 cells were incubated with LPS $(100 \mathrm{ng} / \mathrm{ml})$ in order to stimulate TNF synthesis. SNAP was added for the whole in- 
cubation period or for the last $6 \mathrm{~h}$. PAPA-NO was added for the last $3 \mathrm{~h}$ of the incubation period. After incubation the medium was collected and the concentrations of nitrite were measured as described below. The cells were incubated in fresh medium for an additional $45 \mathrm{~min}$ in the presence or absence of PMA (in the case of MBE-SV and P388/D1 cells) or ionomycin (in the case of ADAM17-- $\mathrm{TNF}^{+}$cells). The level of murine TNF released from P388/D1 cells and TNFR1 released from MBE-SV cells was measured as described previously. Human TNF released from ADAM17-I-TNF ${ }^{+}$cells was measured by ELISA using polyclonal anti-hTNF as a capture antibody and monoclonal murine anti-hTNF followed by HRP-conjugated anti-murine IgG as detection antibodies.

Northern blot analysis. Total RNA was extracted from MBE-SV and P388/D1 cells after incubation with the cytokines or the NO donors by the method of Chomczynski and Sacchi (1987). Equal amounts of RNA $(10 \mu \mathrm{g})$ were fractionated by electrophoresis under denaturing conditions in a $1 \%$ agarose-formaldehyde gel and transferred to Hybond-NX membrane (Amersham Biociences, Little Chalfont, UK). Probes for muADAM17 cDNA were obtained by digestion of pcDNA3.1/ muADAM17 with NotI and KpnI. The membranes were hybridized overnight at $65^{\circ} \mathrm{C}$ with the relevant probe labeled with $\left[\alpha{ }^{32} \mathrm{P}\right] \mathrm{dCTP}$ by random priming using High Prime DNA Labeling system (Roche, Basel, Switzerland). After extensive washing the blots were exposed to an X-ray film or to a phosphoimager screen and the autoradiograms were analyzed using Personal Molecular Imager FX (BioRad, Hercules, CA, USA) and Quantity One software (BioRad). Autoradiographic signals were normalized to the intensity of ethidium bromide-stained $28 \mathrm{~S}$ rRNA after subtraction of background.

Nitrite assay. Nitrite concentration in the medium was determined by a microplate assay. Briefly, $100 \mu \mathrm{l}$ aliquots of culture media were incubated with equal volumes of Griess reagent (1\% sulfanilic acid/0.1\% $N$-(1-naphtyl)ethylenediamine dihydrochloride (Sigma) in 2.5\% $\mathrm{H}_{3} \mathrm{PO}_{4}$ ) at room temperature for $10 \mathrm{~min}$. The absorbance at $545 \mathrm{~nm}$ was measured with a microplate reader. Nitrite concentration was determined by using dilutions of sodium nitrite in medium as a standard.

Cytotoxicity assay. The potential cytotoxic effects of endogenous NO and of NO donors was determined by the MTT test (Celis, 1998). Following the incubation of the cells with the cytokines or the NO donors, the medium was replaced with fresh medium containing MTT $(0.5 \mathrm{mg} / \mathrm{ml})$ and the cells were incubated for an additional $6 \mathrm{~h}$. The absorbance of solubilized formazan was measured at $562 \mathrm{~nm}$.
Zymography. Proteins in media collected after the incubation of the cells with the cytokines or the NO donors were resolved by SDS/PAGE under non-reducing conditions in a gel containing $1 \%$ gelatin. Next, the gels were washed extensively for $2 \mathrm{~h}$ in $2.5 \%$ solution of Triton X-100 in deionized water, incubated overnight at $37^{\circ} \mathrm{C}$ in reaction buffer (10 $\mathrm{mM} \mathrm{CaCl}_{2}, 0.15 \mathrm{M} \mathrm{NaCl}, 50 \mathrm{mM}$ Tris, $\mathrm{pH}$ 7.0) and stained with Coomassie brilliant blue. The zymograms were analysed using Fluor-S Multi Imager and Quantity One software.

Flow cytometric analysis. The ADAM17-/$\mathrm{TNF}^{+}$cells were stained according to standard procedures with murine anti-hTNF and FITC-conjugated anti-murine IgG and the staining of the cells was analyzed vs. an isotype control on a FACScan flow cytometer (Becton Dickinson, USA) using Cell-Quest software.

Protein biosynthesis. $\left[{ }^{3} \mathrm{H}\right]$ leucine (Amersham) was added to the culture medium of the cells during the incubation with the NO donors for the whole incubation periods (in the case of the short incubations) or for the last $6 \mathrm{~h}$ of $24 \mathrm{~h}$-incubation. The incorporation of $\left[{ }^{3} \mathrm{H}\right]$ leucine into TCA-precipitated proteins present in the culture medium as well as in cell lysates was measured using a beta-scintillation counter (Wallac 1414).

Statistical analysis. All data comes from at least 3 independent repeats of experiments performed at least in triplicates, unless indicated otherwise. Statistical analysis was performed using Student's $t$-test with $P<0.05$ considered significant.

\section{RESULTS}

\section{Lack of effect of endogenous or exogenous nitric oxide on ADAM17 mRNA level}

We have previously shown that the expression of ADAM17, the major TNF sheddase, is upregulated by pro-inflammatory cytokines in murine endothelial cells (MBE-SV) (Bzowska et al., 2004). This stimulatory effect was not observed in the P388/D1 monocyte/macrophage cell line in which the basal level of ADAM17 mRNA is very high. Since the cytokine-mediated activation of cells, including MBE and P388/D1, results in the synthesis of large amounts of nitric oxide (NO) due to iNOS induction we decided to analyze its effect on ADAM17 expression. The highest expression of iNOS in MBE-SV can be achieved by stimulating the cells with three cytokines (TNF+IL-1 $\beta+\mathrm{IFN} \gamma$ ), whereas in P388/D1 it requires stimulation with IL$1 \beta$, IFN $\gamma$ and LPS. The levels of NO, endogenously produced or released from NO donors, can be esti- 
A

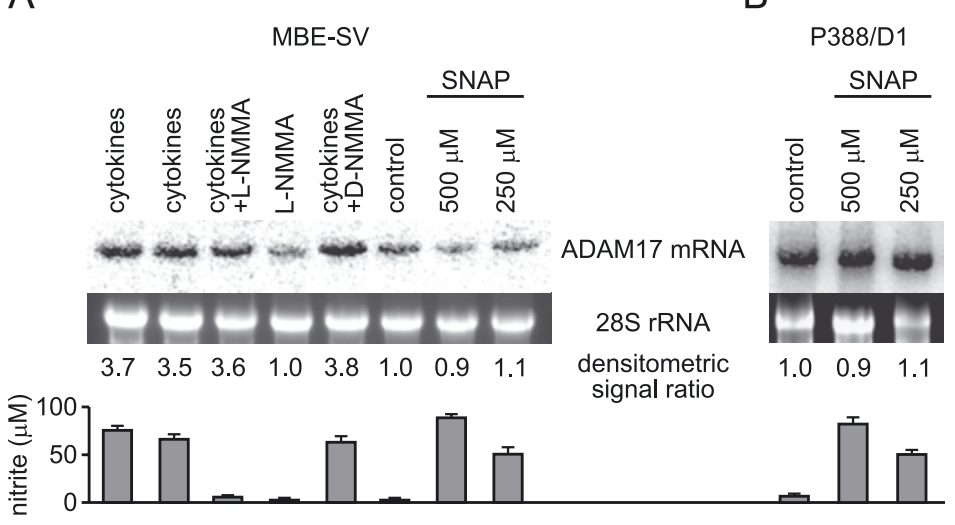

Figure 1. Northern blotting analysis of the effect of nitric oxide on ADAM17 mRNA level in MBE-SV and P388/D1 cells.

A. MBE-SV cells were incubated for $24 \mathrm{~h}$ with medium alone (control), with L-NMMA, with the cytokines TNF, IL-1 $\beta$ and IFN $\gamma$ in the presence or absence of L-NMMA or its stereoisomer D-NMMA, or with SNAP. B. P388/D1 cells were incubated in medium alone or in the presence of SNAP. After incubation, nitrite concentrations were measured in the culture media (lower panel). Numbers indicate the strength of densitometric signals relative to the signal of control sample. Data are representative of 3 experiments. mated by measuring the accumulation of nitrite, a product of $\mathrm{NO}$ oxidation.

To discriminate between the effect of the cytokines and that of nitric oxide produced in response to the cytokines, the cells were incubated in the presence or absence of L-NMMA, a competitive inhibitor of iNOS that almost completely abolished NO synthesis (Fig. 1A). Although endogenous nitric oxide may influence the expression of some genes in MBE cells (Bereta \& Bereta, 1995), it did not affect ADAM17 mRNA level in these cells (Fig. 1A). The levels of ADAM17 mRNA were comparable in MBE-SV stimulated with the cytokines in the absence of L-NMMA (high level of NO) and in the presence of L-NMMA (low level of NO). Similarly, we did not observe any changes in ADAM17 mRNA expression in P388/D1 cells stimulated with the cytokines and LPS in the presence or absence of the iNOS inhibitor (not shown). Also exogenous nitric oxide released from SNAP, an NO donor, had no effect on ADAM17 mRNA level in MBE-SV (Fig. 1A) or P388/D1 cells (Fig. 1B).

Exogenous but not endogenous nitric oxide inhibits the release of ADAM17 substrates

Simultaneously with the analysis of ADAM17 expression we evaluated the activity of the enzyme and, surprisingly, we obtained results contradictory to those of Zhang et al. (2000). In our cell models exogenous nitric oxide did not enhance ADAM17 activity, but rather inhibited the release of ADAM17 substrates to the culture medium. We measured the release of TNF from P388/D1 cells and TNF receptor 1 (TNFR1) from MBE cells during a 45-min incubation of the cells with or without PMA (an ADAM17 activator) that followed 6- or 24-h incubation of the cells with SNAP at different concentrations. The P388/D1 cells released only negligible amounts of TNF without PMA stimulation and thus the effect of SNAP on the basal TNF release was not analyzed. However, the amount of TNF released from the cells ac- tivated with PMA was strongly decreased by SNAP. The strongest inhibition, close to $70 \%$, was observed for the cells incubated for $24 \mathrm{~h}$ with $500 \mu \mathrm{M}$ SNAP, although the effect of $50 \mu \mathrm{M}$ SNAP was already significant (Fig. 2). Less pronounced effects were observed after 6-h incubation of the cells with SNAP (47\% inhibition at $500 \mu \mathrm{M}$ SNAP), although the decomposition of the NO donor was already complete as the concentrations of nitrite in the media were the same as in the case of the 24-h incubation (Fig. 2). MTT assay performed after 6- and 24-h incubation of P388/D1 cells with the NO donor demonstrated that it did not influence the cell viability or metabolism (not shown).

SNAP affected also basal- and PMA-activated release of TNFR1 from MBE-SV cells (Fig. 3A). Nitric oxide seemed to have a stronger impact on the PMA-activated process. Similarly to the inhibition of TNF shedding from P388/D1 cells, also the inhibition of TNFR1 shedding from MBE-SV cells was more pronounced after prolonged incubation of the cells with SNAP (55\% inhibition after $24 \mathrm{~h}$ vs. $41 \%$ after $6 \mathrm{~h}$ at $500 \mu \mathrm{M}$ SNAP). Unlike the P388/D1 cells, MBE-SV cells exposed to SNAP at high concentrations (500 and $250 \mu \mathrm{M}$ ) for $24 \mathrm{~h}$ showed a moder-

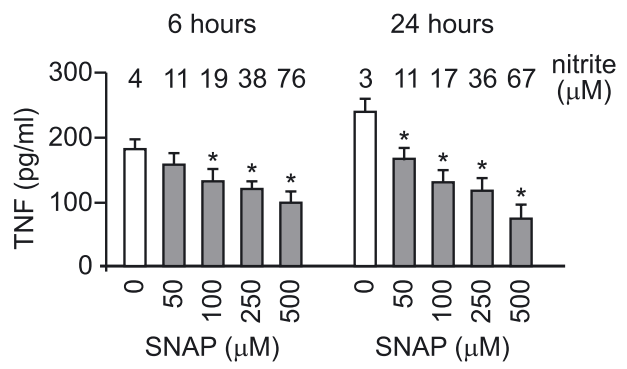

Figure 2. Influence of SNAP on TNF release from P388/ D1 cells.

P388/D1 cells were incubated for 6 or $24 \mathrm{~h}$ with various concentrations of SNAP. At the end of the incubation, nitrite concentration was measured in the medium. After medium replacement, PMA was added for additional $45 \mathrm{~min}$ and the level of TNF released to the medium was measured by ELISA. ${ }^{*} P<0.05$. 


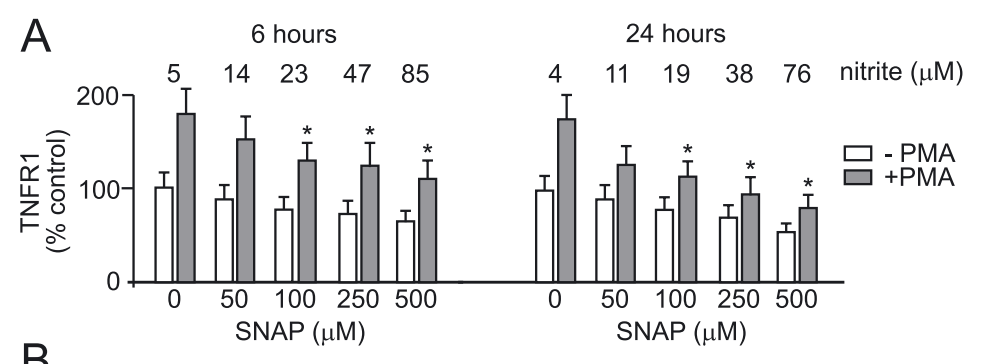

B

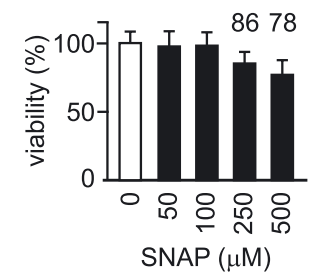

ately decreased ability to reduce tetrazolium salt in the MTT assay (22 and 14\%, respectively), which may indicate that high levels of $\mathrm{NO}$ influenced cell viability or oxidative metabolism to some extent (Fig. 3B).

Although the NO donor strongly inhibited the release of ADAM17 substrates, no such effect was observed for endogenously produced nitric oxide. The levels of TNF in the medium of P388/D1 cells did not change upon stimulation of the cells with the cytokines under conditions that allowed nitric oxide synthesis (in the absence of L-NMMA) nor in the presence of L-NMMA, which prevented NO synthesis (Fig. 4A). The treatment of MBE-SV cells with the cytokines resulted in a significant increase in sTNFR1 release to the culture medium due to the stimulation of ADAM17 expression (Bzowska et al., 2004). However, the level of sTNFR1 release did not depend much on the synthesis of NO, since the presence of the iNOS inhibitor did not influence
Figure 3. Influence of SNAP on TNFR1 release from MBE-SV cells.

MBE-SV cells were incubated for 6 or $24 \mathrm{~h}$ with various concentrations of SNAP. At the end of the incubation, nitrite concentration was measured in the medium. After medium replacement, the cells were incubated in the presence or absence of PMA for additional $45 \mathrm{~min}$. A. Levels of TNFR1 released to the medium measured by ELISA. B. Cell viability/mitochondrial activity measured by MTT assay. ${ }^{*} P<0.05$. the level of sTNFR1 in the medium of MBE-SV cells (Fig. 4B). Even lowering of the volume of the culture medium, which resulted in an increase of nitrite concentration to a level similar to that obtained using SNAP led only to a slight inhibition of TNFR1 release to the medium (Fig. $4 \mathrm{C}$ ).

\section{The effect of exogenous nitric oxide is not limited to inhibition of ADAM17 activity}

We then investigated whether the shedding inhibition by exogenous nitric oxide was limited to inhibiting ADAM17 activity. We considered the possibility that nitric oxide may affect the activity of a whole group of zinc metalloproteases with similar active centers, since reactive nitrogen species may influence zinc-containing proteins. Therefore, we analyzed the effect of SNAP on the release of TNF from ADAM17-/- $\mathrm{TNF}^{+}$fibroblasts as well as on the activity of matrix metalloproteases se-
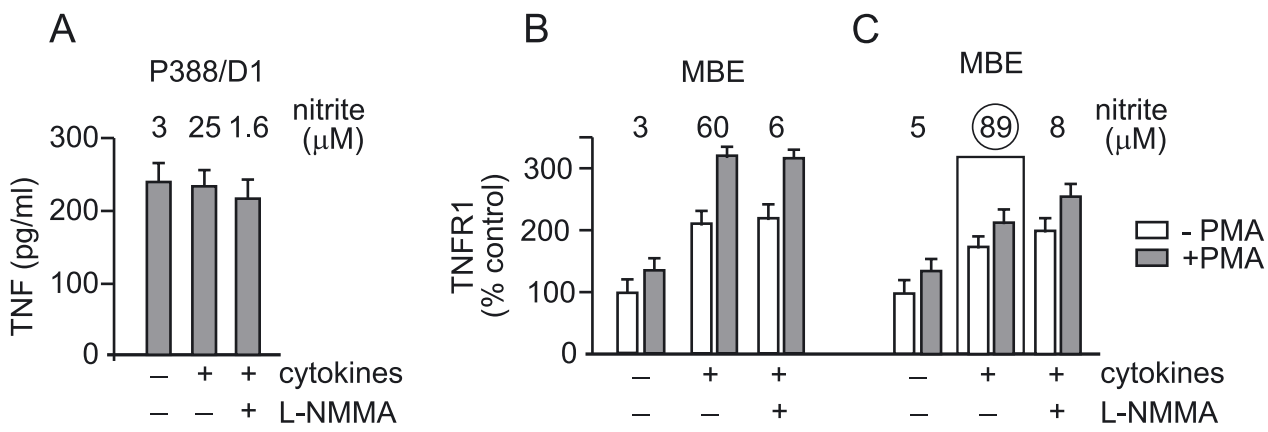

Figure 4. Influence of endogenous nitric oxide on TNF and TNFR1 release from P388/D1 and MBE-SV cells.

A. P388/D1 cells were incubated for $24 \mathrm{~h}$ in medium alone (control), with IL-1 $\beta+$ IFN $\gamma+$ LPS, or with IL- $1 \beta+$ IFN $\gamma+$ LPS in the presence of L-NMMA. After medium replacement, the incubation was continued for additional 45 min in the presence of PMA and the concentration of TNF released to the medium was measured by ELISA. B and C. Cells were incubated for $24 \mathrm{~h}$ with medium alone (control) or with the cytokines TNF, IL-1 $\beta$, IFN $\gamma$ in the presence or absence of L-NMMA. After medium replacement, the incubation was continued for additional $45 \mathrm{~min}$ in the presence or absence of PMA and the level of TNFR1 in the medium was measured using ELISA. B. the cells were incubated in a standard volume of the medium $(100 \mu \mathrm{l})$. C. The cells were incubated in a decreased volume of the medium $(50 \mu \mathrm{l})$. After incubation of the cells with the cytokines (or the cytokines and LPS) nitrite concentration was measured in culture medium. 
A

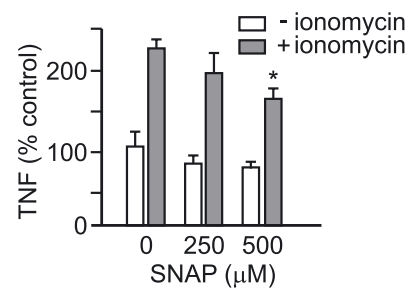

B

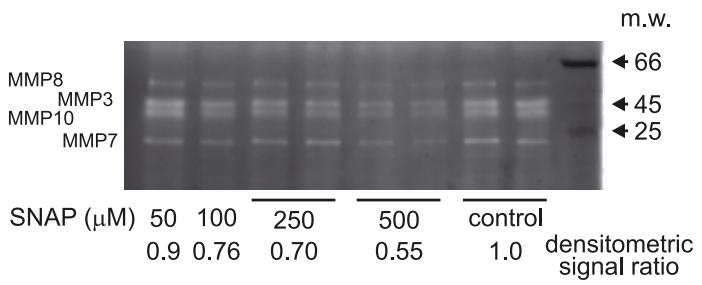

Figure 5. Influence of exogenous nitric oxide on the activity of metalloproteases other than ADAM17.

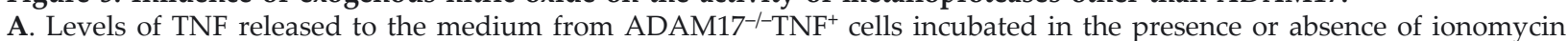
after their 6-h exposure to SNAP, measured by ELISA. B. Activity of MMPs released to the medium by MBE-SV cellsduring their 6-h exposure to various concentrations of SNAP, estimated by zymography. Numbers indicate the strength of densitometric signals relative to the signal of control sample. Data are representative of 3 experiments. ${ }^{*} P<0.05$.

creted by MBE-SV cells. We have documented that ADAM10 is mostly responsible for the shedding of TNF from ADAM17-l-TNF ${ }^{+}$cells (Mężyk-Kopeć et al., 2009). The moderate inhibition of TNF release from ADAM17--- $\mathrm{TNF}^{+}$, both unstimulated and activated with ionomycin (an activator of ADAM10) after exposure of the cells to SNAP indicated that also ADAM10-mediated shedding was impaired by exogenous nitric oxide (Fig. 5A), although to a much lesser extent than PMA-activated shedding from P388/D1 and MBE-SV cells (see Figs. 2 and 3). SNAP did not affect the viability of ADAM17--I-TNF ${ }^{+}$ cells (not shown). Similarly, the activities of all collagen-specific MMPs were diminished in the medium of MBE-SV cells treated with SNAP (Fig. 5B). However, unexpectedly, when SNAP was added for $6 \mathrm{~h}$ not directly to the cell culture but to the medium collected after cell incubation, no inhibitory effect of SNAP was observed (data not shown). This finding indicated that nitric oxide did not influence the enzymatic activity of MMPs, but rather their synthesis, intracellular transport or secretion. Based on this observation it seems plausible that also the effect of exogenous nitric oxide on proteins of the ADAM family does not consist in inhibiting their enzymatic activity.

\section{PAPA-NO, another NO donor, strongly inhibits the release of ADAM17 substrates}

The discrepancy between our results and those of Zhang et al. (2000) might result from the different NO donors used. Therefore, we repeated some of our experiments using the same NO donor (PAPA-NO) with the same concentrations and the same incubation period $(3 \mathrm{~h})$ as applied by Zhang et al. (2000). The kinetics of NO release from PAPA-NO is very fast; the plateau of nitrite concentration is obtained already in $5 \mathrm{~min}$ after solubilization of the compound; moreover, the concentrations of PAPA$\mathrm{NO}$ that were used resulted in the accumulation of enormous, non-physiological concentrations of nitrite $(>600 \mu \mathrm{M}$ for $1 \mathrm{mM}$ PAPA-NO). Under such conditions the inhibitory effect of PAPA-NO on the shedding of ADAM17 substrates was even stronger than that of SNAP (Fig. 6).

\section{NO donors influence protein synthesis}

Our finding that exogenous nitric oxide did not influence the enzymatic activity of MMPs led us to the question about the mechanisms, other than impaired enzyme effectiveness, that could be

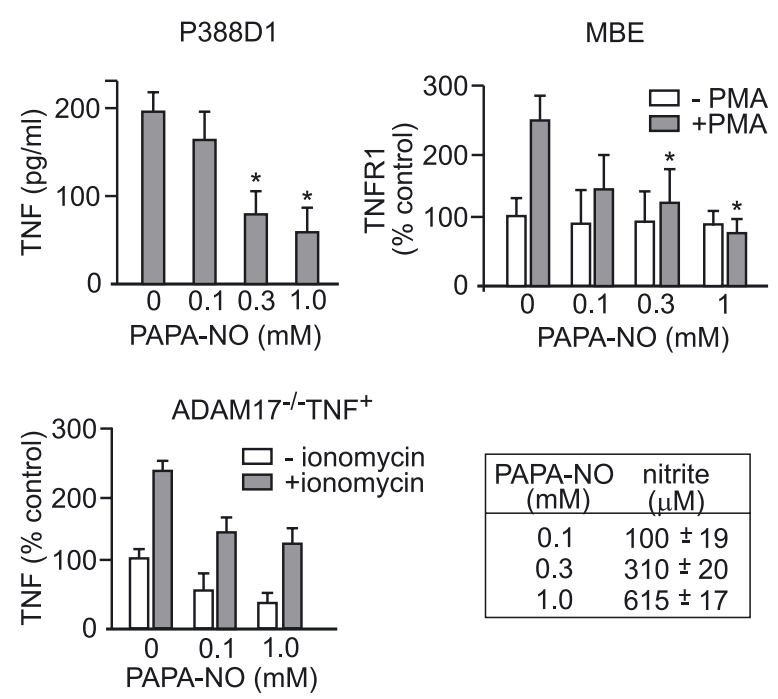

Figure 6. Effect of PAPA-NO on the release of TNF from P388/D1 and ADAM17- ${ }^{-/}$TNF $^{+}$cells and TNFR1 from MBE-SV cells.

Cells were incubated for $3 \mathrm{~h}$ with different concentrations of PAPA-NO and after medium replacement, the incubation was continued for additional $45 \mathrm{~min}$ in the absence or presence of PMA (P388/D1 and MBE-SV) or ionomycin $\left(\mathrm{ADAM} 17^{-/-} \mathrm{TNF}^{+}\right.$). Concentrations of TNF or TNFR1 in the media were measured by ELISA. Table shows the concentrations of nitrite generated from different concentrations of PAPA-NO. Data concerning the influence of PAPA-NO on ionomycin-treated ADAM17-l- $\mathrm{TNF}^{+}$cells come from a single experiment performed in triplicate. ${ }^{*} P<0.05$. 

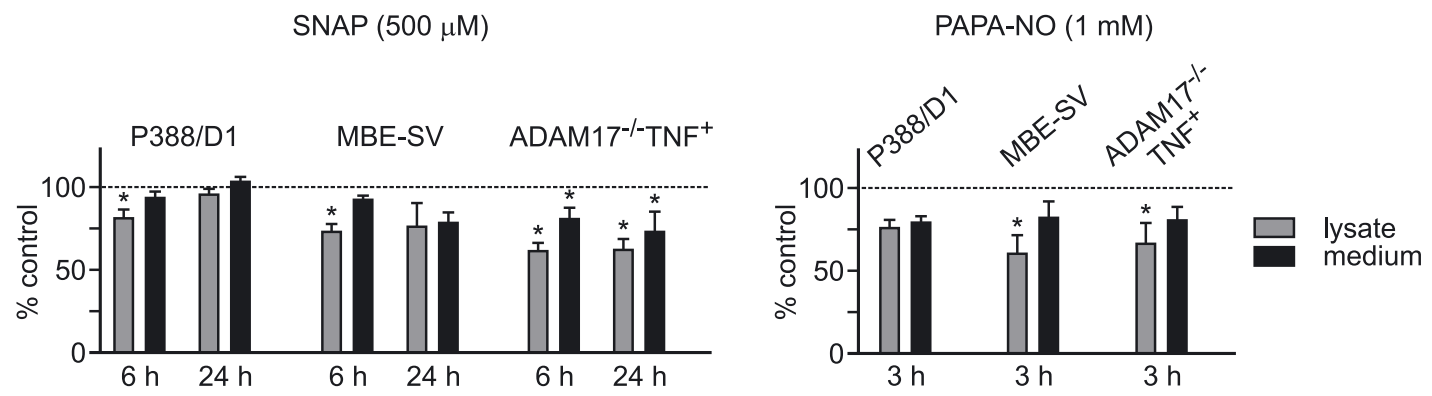

Figure 7. Effect of NO donors on total protein synthesis. Incorporation of $\left[{ }^{3} \mathrm{H}\right]$ leucine into proteins was measured in lysates and culture media of cells exposed to NO donors. ${ }^{*} P<0.05$.

responsible for the decreased release of ADAM17 substrates. We hypothesized that it could result from the inhibition of more general processes in the cells, such as protein synthesis or intracellular trafficking. We therefore analyzed the incorporation of $\left[{ }^{3} \mathrm{H}\right]$ leucine into cellular and secreted proteins in cultures of MBE-SV, P388/D1 and ADAM17-l- TNF $^{+}$cells treated with SNAP for 6 or $24 \mathrm{~h}$ or PAPA-NO for $3 \mathrm{~h}$. We found that both NO donors inhibited protein synthesis to some extent in all cell lines studied and that the effect of PAPA-NO $(1 \mathrm{mM})$ was stronger than that of SNAP $(500 \mu \mathrm{M})$ (Fig. 7). PAPA-NO at $0.1 \mathrm{mM}$ influenced protein synthesis almost as efficiently as at $1 \mathrm{mM}$. The final accumulation of nitrite in the SNAP solution $(500 \mu \mathrm{M})$ was around $70 \mu \mathrm{M}$ and in PAPA-NO $(100 \mu \mathrm{M})$ around $100 \mu \mathrm{M}$. The stronger effect of PAPA-NO may have resulted from the different kinetics of NO release from both compounds. The immediate decomposition of PAPA-NO may lead to a peak of nitric oxide concentration much higher than in the case of SNAP. The inhibition of $\left[{ }^{3} \mathrm{H}\right]$ leucine incorporation into cellular proteins was more pronounced than into the pool of proteins released to the medium, which suggested that nitric oxide did not affect overall protein secretion. Comparing different cell lines, we did not observe a correlation between the level of shedding inhibition and the level of the inhibition of protein synthesis. The highest inhibition of shedding was observed for P388/D1 cells, in which the protein synthesis was the least affected. Moreover, the inhi-

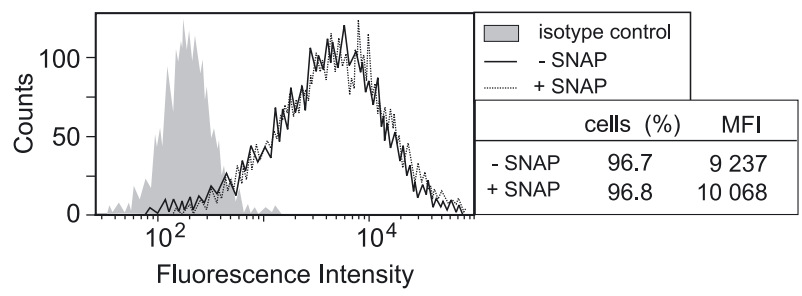

Figure 8. Flow cytometric analysis of TNF surface level on ADAM17 ${ }^{-/-}$TNF $^{+}$cells.

Cells were exposed for $6 \mathrm{~h}$ to SNAP $(500 \mu \mathrm{M})$. Data are representative of 3 experiments performed in duplicates. bition of TNF release from P388/D1 cells was more pronounced $24 \mathrm{~h}$ after adding SNAP to the medium, whereas the inhibition of protein synthesis was stronger after $6 \mathrm{~h}$, probably due to a temporary effect of nitric oxide on this process.

\section{NO donors do not influence the surface levels of TNF on ADAM17 ${ }^{-l-} \mathrm{TNF}^{+}$cells}

The observed decrease in the amount of TNF and TNFR1 released to the medium could also be a result of a diminished level of these proteins in the membrane due to impaired protein synthesis, which could have caused a decreased availability of substrates for ADAM17 or ADAM10. We were unable to detect TNF on the surface of P388/D1 or TNFR1 on the surface of MBE-SV by flow analysis; we therefore analyzed the effect of exogenous nitric oxide on TNF level on ADAM17-l- $\mathrm{TNF}^{+}$which express high levels of TNF on the cell surface. We did not observe significant changes in the number of TNF-positive cells or in the mean fluorescence intensity after the exposure of the cells to SNAP for $6 \mathrm{~h}$ (Fig. 8).

\section{DISCUSSION}

Cytokines stimulate ADAM17 expression in murine endothelial cells (Bzowska et al., 2004). In these studies we found that nitric oxide generated in MBE-SV cells in response to inflammatory mediators did not modulate cytokine-upregulated ADAM17 mRNA level. Similarly, endogenous nitric oxide had no influence on the already high level of ADAM17 mRNA in P388/D1 cells. Endogenous nitric oxide had also no effect on the levels of ADAM17 substrates, TNF and TNFR1, released to the medium after $24 \mathrm{~h}$ stimulation of P388/D1 or MBE-SV cells. Only at the highest possible concentration of endogenous NO resulting in the accumulation of almost $90 \mu \mathrm{M}$ nitrite in the medium of MBE-SV cells was a slight decrease of TNFR1 level observed in the medium. 
The exposure of cells to the NO donor SNAP did not influence ADAM17 expression but significantly reduced the levels of ADAM17 substrates released to the culture medium. Our results are seemingly contradictory to those of Zhang et al. (2000) who showed that another NO donor, PAPA-NO, activated ADAM17, which resulted in the increased ratio of soluble versus cell-bound ADAM17 substrates. One possibility was that the discrepancy between the Zhang's results and ours consisted in the type of the NO donor used. We applied moderate concentrations of SNAP that slowly releases NO (a maximum level of nitrite is observed $6 \mathrm{~h}$ after adding the compound to the medium) whereas Zhang and coworkers used high concentrations of PAPA-NO that immediately releases all nitric oxide (Fig. 9). However, we rejected this hypothesis since in our hands PAPA-NO also inhibited shedding of ADAM17 substrates. The possibility that the discrepancy is due to the use of distinct cell lines is not very likely (although not dismissible) since both studies included cell lines of macrophage origin and, moreover, the mechanism of NO-mediated ADAM17 activation proposed by Zhang and coworkers is so general that it should apply to all cells.

The major difference between our and Zhang's experiments lay in their scheme and timecourse. Zhang and coworkers measured the release of ADAM17 substrates during 2- or 3-h incubation of the cells with the NO donor, thus they analyzed the immediate effects of exogenously generated NO, whereas we, in order to examine the effect of $\mathrm{NO}$ on PMA-induced shedding, had to replace the medium with a fresh one to avoid the high background of ADAM17 substrates present in the medium before the addition of PMA. Thus we analyzed late effects of nitric oxide on the cells. The results of Zhang and coworkers also showed that the ratio of soluble to membrane TNF after 2-h incubation was significantly higher than that observed after 3-h incubation of Mono Mac 6 cells in the presence of LPS, PMA and PAPA-NO (Zhang et al., 2000), which may suggest that the stimulatory effect of nitric oxide on ADAM17 is transitory.

What could be the reason for the diminished levels of TNF and TNFR1 released from the surface of the cells after their exposure to the NO donors? We can exclude the hypothesis that the mechanism involves an NO signaling pathway, the activation of a soluble guanylate cyclase and cGMP-dependent protein kinase, since in that case the effects would be observed already at much lower (nanomolar) NO concentrations. Nitric oxide and NO-derived reactive nitrogen species (RNS), present at high concentrations, may react with proteins leading to S-nitrosylation of thiol groups, nitration of tyrosine residues, inactivation of heme, or disruption of metal-sulfide clusters. This may affect the activity of numerous proteins (for instance kinases, transcription factors, enzymes of electron transport chain, G-proteins) involved in diverse processes such as oxidative metabolism, signal transduction, transport and trafficking.

Our data suggest complex mechanisms of the inhibition of TNF and TNFRI release from the cells that may result from the NO RNS-mediated impairment of several distinct processes. PMA-induced shedding was more affected than the basal process, which may suggest that exogenous NO inhibited ADAM17 activity or its activation. Since the mechanism of PMA-mediated stimulation of ADAM17 activity is still unclear, it was not possible to investigate specific influence of $\mathrm{NO}$ on the molecules involved in this process. However, we also observed moderate inhibition of ADAM10-induced TNF shedding from the cells deprived of active ADAM17 and inhibition of MMPs activity in MBE-SV cells treated with SNAP. This finding together with the observation that the effect of a 24-h incubation of the cells with SNAP was stronger than that of a 6-h incubation suggests the existence of additional, more general mechanisms. They do not include an impaired cell viability since it was not affected by SNAP or PAPA-NO. The slight decrease in the reduction of formazan salt by MBE-SV exposed to SNAP for $24 \mathrm{~h}$ probably resulted from the inhibition of oxidative metabolism. The impact of nitric oxide on the mitochondrial oxidative chain in MBE cells was already suggested by the results of our previous work in which we found strong NO-mediated stimulation of the expression of a glycolytic enzyme, GAPDH, that may compensate for diminished energy supply by oxidative metabolism (Bereta \& Bereta, 1995).

A decreased protein synthesis might be partially responsible for the diminished level of TNF released from ADAM17--- $\mathrm{TNF}^{+}$cells exposed to $\mathrm{NO}$ donors. However, the small decrease in protein synthesis in MBE-SV and especially in P388/D1 cells suggested that this process may only have a minor contribution to the limited shedding of TNFR1 or TNF in these cells after their incubation with NO donors.

It is also possible that $\mathrm{NO}$ may specifically affect the expression of TNF and TNFR1, leading to a limited accessibility of the substrates to secretases. Indeed, exogenous NO was shown to inhibit cytokine synthesis in alveolar macrophages, but those authors used high concentration of the donor that led to the generation of $200-750 \mu \mathrm{M}$ nitrite in the culture medium. It is possible that the observed effect resulted from the inhibition of NF- $\kappa \mathrm{B}$ binding to the TNF promoter. However, it has been shown that nitric oxide inhibits NF- $\kappa \mathrm{B}-\mathrm{DNA}$ interaction only at high concentrations $(>250 \mu \mathrm{M})$, whereas at lower ones it promotes NF- $\mathrm{kB}$-mediated activation of transcription (Umansky et al., 1998; von Knethen et al., 
1999). The transcription of TNF was shown to be stimulated in U937 cells by NO through the inhibition of interaction of Sp1 with its binding site in TNF promoter (Zhang et al., 2003). Moreover, nitric oxide, through the activation of p38 MAP kinase, stabilizes TNF mRNA (Wang et al., 2008). Thus we should expect an increase rather than a decrease in TNF level in our experimental settings. There are only scarce data on the regulation of TNFR1 expression, which may suggests that this process is not significantly regulated. We have shown that in $\mathrm{ADAM} 17^{-1-} \mathrm{TNF}^{+}$ cells the level of TNF on the cell surface was not diminished after a 6-h incubation with SNAP, thus it can be concluded that the decrease in shedding occurred even though the availability of the substrate to the enzyme was not changed. One could speculate that the decrease in TNF shedding should result in an increased levels of the membrane cytokine. We hypothesize that the unchanged surface level of TNF is the outcome of a decreased protein synthesis and decreased shedding.

Zhang et al. (2000) suggested that the stimulation of ADAM17 activity by nitric oxide consisted in nitrosylation of the crucial cysteine residue in the inhibitory prodomain which led to the activation of latent ADAM17. They showed that a prodomainderived peptide containing so-called cysteine swich inhibited recombinant ADAM17 lacking the prodomain and thus constitutively active, and that PAPANO reversed this inhibition through S-nitrosylation of the cysteine residue in the peptide (Zhang et al., 2000).

However, it has been shown recently that the ADAM17 prodomain has a crucial role not only in the inhibition of ADAM17 activity but also in its maturation. It acts as an ADAM17 chaperone and is indispensable for its efficient synthesis. The recombinant protein lacking the prodomain undergoes intracellular degradation, probably through the reticulum-proteasome pathway (Milla et al., 2006). Thus, it seems possible that nitric oxide through S-nitrosylation of the cysteine residue within the prodomain activates ADAM17 at the late steps of its biogenesis but inhibits its proper folding and maturation at early stages of the process. This hypothesis could explain the discrepancy between the effects of $\mathrm{NO}$ observed by Zhang and coworkers (2000; 2003) and our group.

The plasma level of nitrite is often used as a marker of nitric oxide synthesis in vivo. It has been shown that in the plasma of healthy volunteers the concentration of nitrite is $0.12 \mu \mathrm{M}$ (Dejam et al., 2005). During septic shock the levels of nitrite/nitrate dramatically increase reaching $17.5 \pm 2.56 \mu \mathrm{M}$ when multiple organ dysfunction (MOD) is not observed and $39.1 \pm 6.67 \mu \mathrm{M}$ in case of MOD occurrence (GomezJimenez et al., 1995). It is possible that locally, at the inflammation sites, NO production followed by nitrite
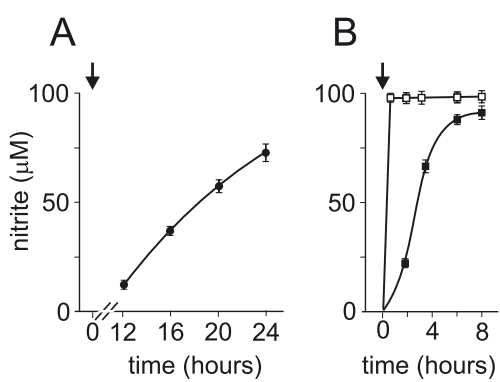

Figure 9. Kinetics of nitrite accumulation following synthesis of endogenous NO or its release from donors. Nitrite concentration was measured (A) in medium of MBE-SV cells subjected to the cytokines or (B) in medium supplemented with NO donors: SNAP (black squares), PAPA-NO (white squares). Arrows indicate the moment of the addition of the cytokines or NO donors to medium.

accumulation is more extensive, but in our opinion it would not exceed the values that are obtained in cell cultures. Therefore, we used in our experiments the concentrations of the $\mathrm{NO}$ donor that resulted in nitrite accumulation levels close to those obtained when the synthesis of endogenous NO was induced. However, the kinetics of endo- and exogenous NO generation are quite different. The kinetics of nitrite accumulation in the culture medium (Fig. 9) may only partially reflect the kinetics of NO synthesis and, since nitrite is the final product of $\mathrm{NO}$ oxidation, it gives no information of the NO concentration during experiments. In the case of endogenous nitric oxide, the compound is produced constantly but at a moderate rate and in the case of donor-derived NO the same (or even higher) levels of nitrite accumulate much more rapidly (for PAPA-NO, immediately), which indicates that the levels of active NO is temporarily much higher although transient. Moreover, cytokines, simultaneously with the induction of iNOS expression, modulate the expression of a whole set of genes that may influence the occurrence of RNS and the effect of nitric oxide generated. This may explain the differences in the effect of exogenous versus endogenous $\mathrm{NO}$ in our experiments.

In conclusion, we have shown that endogenous nitric oxide produced by activated MBE cells and P388/D1 cells has no effect on ADAM17 mRNA level and on the shedding of TNFR1 and TNF from the cell surface. The exposure of cells to SNAP-derived NO caused a decrease in the levels of TNFR1 and TNF released to the culture medium. The elucidation of the mechanism responsible for this effect requires further studies.

\section{Acknowledgements}

This work was supported by grant 3144/B/ P01/2007/33 from the Ministry of Science and Higher Education. 


\section{REFERENCES}

Althoff K, Reddy P, Voltz N, Rose-John S, Mullberg J (2000) Shedding of interleukin-6 receptor and tumor necrosis factor $\alpha$. Contribution of the stalk sequence to the cleavage pattern of transmembrane proteins. Eur J Biochem 267: 2624-2631.

Arribas J, Ruiz-Paz S (2005) ADAM17. Regulation of ectodomain shedding. In The ADAM family of proteases. Hooper NM, ed, pp 171-197. Springer, New York.

Bereta J, Bereta M (1995) Stimulation of glyceraldehyde3-phosphate dehydrogenase mRNA levels by endogenous nitric oxide in cytokine-activated endothelium. Biochem Biophys Res Commun 217: 363-369.

Black RA, Rauch CT, Kozlosky CJ, Peschon JJ, Slack JL, Wolfson MF, Castner BJ, Stocking KL, Reddy P, Srinivasan S, Nelson N, Boiani N, Schooley KA, Gerhart M, Davis R, Fitzner JN, Johnson RS, Paxton RJ, March CJ, Cerretti DP (1997) A metalloproteinase disintegrin that releases tumour-necrosis factor- $\alpha$ from cells. Nature 385: 729-733.

Blanchot-Jossic F, Jarry A, Masson D, Bach-Ngohou K, Paineau J, Denis MG, Laboisse CL, Mosnier JF (2005) Up-regulated expression of ADAM17 in human colon carcinoma: co-expression with EGFR in neoplastic and endothelial cells. J Pathol 207: 156-163.

Bogdan C (2001) Nitric oxide and the immune response. Nat Immunol 2: 907-916.

Bohgaki T, Amasaki Y, Nishimura N, Bohgaki M, Yamashita Y, Nishio M, Sawada KI, Jodo S, Atsumi T, Koike T (2005) Up regulated expression of tumour necrosis factor \{alpha\} converting enzyme in peripheral monocytes of patients with early systemic sclerosis. Ann Rheum Dis 64: 1165-1173.

Borrell-Pages M, Rojo F, Albanell J, Baselga J, Arribas J (2003) TACE is required for the activation of the EGFR by TGF- $\alpha$ in tumors. EMBO J 22: 1114-1124.

Bzowska M, Jura N, Lassak A, Black RA, Bereta J (2004) Tumour necrosis factor-alpha stimulates expression of TNF- $\alpha$ converting enzyme in endothelial cells. Eur J Biochem 271: 2808-2820.

Chomczynski P, Sacchi N (1987) Single-step method of RNA isolation by acid guanidinium thiocyanate-phenol-chloroform extraction. Anal Biochem 162: 156-159.

Colon AL, Menchen LA, Hurtado O, De Cristobal J, Lizasoain I, Leza JC, Lorenzo P, Moro MA (2001) Implication of TNF- $\alpha$ convertase (TACE/ADAM17) in inducible nitric oxide synthase expression and inflammation in an experimental model of colitis. Cytokine 16: 220226.

Dejam A, Hunter CJ, Pelletier MM, Hsu LL, Machado RF, Shiva S, Power GG, Kelm M, Gladwin MT, Schechter AN (2005) Erythrocytes are the major intravascular storage sites of nitrite in human blood. Blood 106: 734-739.

Ding X, Yang LY, Huang GW, Wang W, Lu WQ (2004) ADAM17 mRNA expression and pathological features of hepatocellular carcinoma. World J Gastroenterol 10: 2735-2739.

Dunn BM (1995) Detection and assay methods. In: Current protocols in molecular biology. Ausubel F, Brent R, Kingston R, Moore D, Seidman J, Smith J, Struhl K, eds, pp 3.6.4-3.6.6. John Wiley \& Sons, New York.

Eriksson S, Chambers BJ, Rhen M (2003) Nitric oxide produced by murine dendritic cells is cytotoxic for intracellular Salmonella enterica sv. Typhimurium. Scand J Immunol 58: 493-502.

Franovic A, Robert I, Smith K, Kurban G, Pause A, Gunaratnam L, Lee S (2006) Multiple acquired renal car- cinoma tumor capabilities abolished upon silencing of ADAM17. Cancer Res 66: 8083-8090.

Garton KJ, Gough PJ, Blobel CP, Murphy G, Greaves DR, Dempsey PJ, Raines EW (2001) Tumor necrosis factor$\alpha$-converting enzyme (ADAM17) mediates the cleavage and shedding of fractalkine (CX3CL1). J Biol Chem 276: 37993-38001.

Garton KJ, Gough PJ, Philalay J, Wille PT, Blobel CP, Whitehead RH, Dempsey PJ, Raines W (2003) Stimulated shedding of vascular cell adhesion molecule 1 (VCAM-1) is mediated by tumor necrosis factor- $\alpha$-converting enzyme (ADAM 17). J Biol Chem 278: 3745937464.

Gomez-Jimenez J, Salgado A, Mourelle M, Martin MC, Segura MR, Peracaula R, Moncada S (1995) L-Arginine: nitric oxide pathway in endotoxemia and human septic shock. Crit Care Med 23: 253-258.

Gomez MI, Sokol SH, Muir AB, Soong G, Bastien J, Prince $S$ (2005) Bacterial induction of TNF- $\alpha$ converting enzyme expression and IL- 6 receptor $\alpha$ shedding regulates airway inflammatory signaling. I Immunol 175: 1930-1936.

Holst-Hansen C, Brünner N (1998) MTT-cell proliferation assay. In: Cell biology: A laboratory handbook. Celis JE, ed, pp 16-18. Academic Press, London.

Horiuchi K, Kimura T, Miyamoto T, Takaishi T, Okada Y, Toyama Y, Blobel CP (2007) Cutting edge: TNF- $\alpha$ converting enzyme (TACE/ADAM17) inactivation in mouse myeloid cells prevents lethality from endotoxin shock. J Immunol 179: 2686-2689.

Kermarrec N, Selloum S, Plantefeve G, Chosidow D, Paoletti X, Lopez A, Mantz J, Desmonts JM, GougerotPocidalo MA, Chollet-Martin S (2005) Regulation of peritoneal and systemic neutrophil-derived tumor necrosis factor- $\alpha$ release in patients with severe peritonitis: role of tumor necrosis factor- $\alpha$ converting enzyme cleavage. Crit Care Med 33: 1359-1364.

MacMicking JD, Nathan C, Hom G, Chartrain N, Fletcher DS, Trumbauer M, Stevens K, Xie QW, Sokol K, Hutchinson N (1995) Altered responses to bacterial infection and endotoxic shock in mice lacking inducible nitric oxide synthase. Cell 81: 641-650.

Mężyk R, Bzowska M, Bereta J (2003) Structure and functions of tumor necrosis factor- $\alpha$ converting enzyme. Acta Biochim Polon 50: 625-645.

Mężyk-Kopeć R, Bzowska M, Potempa J, Bzowska M, Jura N, Sroka A, Black RA, Bereta J (2005) Inactivation of membrane tumor necrosis factor $\alpha$ by gingipains from Porphyromonas gingivalis. Infect Immun 73: 1506-1514.

Mężyk-Kopeć R, Bzowska M, Stalińska K, Chełmicki T, Podkalicki M, Jucha J, Kowalczyk K, Mak P, Bereta J (2009) Identification of ADAM10 as a major TNF sheddase in ADAM17-deficient fibroblasts. Cytokine 46: 309-315.

Milla ME, Gonzales PE, Leonard JD (2006) The TACE zymogen: re-examining the role of the cysteine switch. Cell Biochem Biophys 44: 342-348.

Moss ML, Jin SL, Milla ME, Bickett DM, Burkhart W, Carter HL, Chen WJ, Clay WC, Didsbury JR, Hassler D, Hoffman CR, Kost TA, Lambert MH, Leesnitzer MA, McCauley P, McGeehan G, Mitchell J, Moyer M, Pahel G, Rocque W, Overton LK, Schoenen F, Seaton T, Su JL, Becherer JD (1997) Cloning of a disintegrin metalloproteinase that processes precursor tumour-necrosis factor-alpha. Nature 385: 733-736.

Murray HW, Nathan CF (1999) Macrophage microbicidal mechanisms in vivo: reactive nitrogen versus oxygen intermediates in the killing of intracellular visceral Leishmania donovani. J Exp Med 189: 741-746. 
Peschon JJ, Slack JL, Reddy P, Stocking KL, Sunnarborg SW, Lee DC, Russell WE, Castner BJ, Johnson RS, Fitzner JN, Boyce RW, Nelson N, Kozlosky CJ, Wolfson MF, Rauch CT, Cerretti DP, Paxton RJ, March CJ, Black RA (1998) An essential role for ectodomain shedding in mammalian development. Science 282: 1281-1284.

Reddy P, Slack JL, Davis R, Cerretti DP, Kozlosky CK, Blanton RA, Shows D, Peschon JJ, Black RA (2000) Functional analysis of the domain structure of tumor necrosis factor-alpha converting enzyme. J Biol Chem 275: 14608-14614.

Umansky V, Hehner SP, Dumont A, Hofmann TG, Schirrmacher V, Droge W, Schmitz ML (1998) Co-stimulatory effect of nitric oxide on endothelial NF- $\kappa \mathrm{B}$ implies a physiological self-amplifying mechanism. Eur J Immunol 28: 2276-2282.

von Knethen A, Callsen D, Brune B (1999) NF- $\kappa$ B and AP1 activation by nitric oxide attenuated apoptotic cell death in RAW 264.7 macrophages. Mol Biol Cell 10: 361-372.
Wang S, Zhang J, Zhang Y, Kern S, Danner RL (2008) Nitric oxide-p38 MAPK signaling stabilizes mRNA through AU-rich element-dependent and -independent mechanisms. J Leukoc Biol 83: 982-990.

$\mathrm{Xu} \mathrm{H}$, Uysal KT, Becherer JD, Arner P, Hotamisligil GS (2002) Altered tumor necrosis factor- $\alpha$ (TNF- $\alpha$ ) processing in adipocytes and increased expression of transmembrane TNF- $\alpha$ in obesity. Diabetes 51: 1876-1883.

Zhang Z, Kolls JK, Oliver P, Good D, Schwarzenberger PO, Joshi MS, Ponthier JL, Lancaster R Jr (2000) Activation of tumor necrosis factor- $\alpha$ converting enzyme-mediate ectodomain shedding by nitric oxide. J Biol Chem 275: 15839-15844.

Zhang J, Wang S, Wesley RA, Danner RL (2003) Adjacent sequence controls the response polarity of nitric oxide-sensitive Sp factor binding sites. J Biol Chem 278: 29192-29200. 